\title{
What does the vibration therapy add? A quasi- experimental, pilot study on the short term effects of whole-body vibration as mode of exercise for nursing home residents aged $80+$
}

\author{
FRANCISCO ÁLVAREZ BARBOSA ${ }^{1}$, ROSA MARIA ALFONSO ROSA ${ }^{2}$, JESÚS DEL POZO CRUZ² \\ ${ }^{1}$ Cardenal Spinola University Studies Center (CEU), University of Sevilla, Spain \\ ${ }^{2}$ Faculty of Education Sciences, University of Sevilla, Spain
}

\begin{abstract}
Aims: To compare the responses of nursing home residents aged $80+$ to an 8 weeks exercise program performed on a vibratory device and to the same exercise program preformed without vibration on lower limb performance, functional dependence and quality of life. Methods: Lower limb performance was evaluated using the 30 seconds Chair Sit to Stand test. Functional mobility was assessed using the timed up and go test. Postural stability was measured using a force platform. The Barthel Index was used to assess functional dependence and the EuroQol was used to evaluate Health-Related Quality of Life. 44 participants were allocated to the whole-body vibration group $(n=15)$, non-vibration group $(n=15)$ or to the control group $(n=$ 14). Results: Significant differences were detected in favour of the whole-body vibration group in lower limb muscle performance $(p=0.001)$, mobility $(p=0.001)$, functional independence $(p=0.009)$ and quality of life $(p<0.001)$ as compared to the control and non-vibration groups. Conclusions: Whole body vibration based interventions may add additional benefits to conventional exercise programs in terms of lower limb muscle performance, functional dependence and quality of life among nursing home residents over 80 years. Keywords: Whole body vibration; Nursing home; Quality of life; Functional mobility.
\end{abstract}

Cite this article as:

Álvarez, F., Alfonso, R.M., \& del Pozo, J. (2018). What does the vibration therapy add? A quasiexperimental, pilot study on the short term effects of whole-body vibration as mode of exercise for nursing home residents aged 80+. Journal of Human Sport and Exercise, 13(4), 810-822. doi:https://doi.org/10.14198/jhse.2018.134.09

\footnotetext{
Corresponding author. Faculty of Education Sciences, University of Sevilla, Spain

E-mail: roalrosa@us.es

Submitted for publication March 2018

Accepted for publication June 2018

Published in press July 2018

JOURNAL OF HUMAN SPORT \& EXERCISE ISSN 1988-5202

(c) Faculty of Education. University of Alicante

doi:10.14198/jhse.2018.134.09
} 


\section{INTRODUCTION}

Aging is associated with a number of changes in the functionality of lower limbs such as a loss of muscle strength, poorer balance, a minor postural control or a decrease of gait ability (Kadono \& Pavol, 2013; SousaVictor et al., 2015; Wolfson, 2001). Aging causes a high prevalence in the number of falls suffered by older people, being even more prevalent in institutionalized older people (Rubenstein \& Josephson, 2002), since they have lower limb performance when compared with their peers living in the community (Nitz \& Josephson, 2011). This leads them to be more dependent and to have a lower quality of life (Almomani et al., 2014). Hence, physical performance among nursing home residents aged over 80 is imperative.

There is strong evidence that exercise could improve physical function, increasing the speed of gait and balance, mobility and ability to perform activities of daily living (ADLs) independently (Chou, Hwang \& Wu, 2012; Gine-Garriga et al., 2014), but an adequate intensity and duration is required (Sherrington et al., 2008; Sherrington et al., 2011). Such programs might not be well tolerated by frail people due to fatigue (Pollock, Martin \& Newham, 2012). Thus, there is a need for alternatives to improve modifiable factors such as strength and mobility and ultimately improve the functional dependence and quality of life of nursing home residents aged over 80 .

Whole-body vibration (WBV) training has become increasingly popular over the past several years as an alternative to conventional exercise programs. It is hypothesized that WBV enhances the neuromuscular system by increasing the sensitivity of the stretch reflex. Furthermore, vibration appears to inhibit activation of antagonist muscles through inhibitory neurons, thus altering the intramuscular coordination patterns leading to a decreased braking force around the joints stimulated by vibration (Cardinale \& Bosco, 2003). Hence, WBV has the potential to improve functional mobility, muscle strength and postural control (Cardinale \& Bosco, 2003), suggesting that whole-body vibration might be an effective intervention for falls. Furthermore, WBV training minimizes the need for conscious exertion (Bogaerts et al., 2009), which makes this kind of exercise therapies a suitable alternative for individuals unable or unwilling to do strength and balance training (Lam et al., 2012) such as nursing home residents aged 80+.

Different studies have reported on the feasibility and effectiveness of WBV to improve mobility, strength, balance, functional dependence or quality of life among older adults living in nursing homes when compared to non-exercise control groups (Bautmans et al., 2005; Bogaerts et al., 2011; Bruyere et al., 2005; Sievanen et al., 2012) or physiotherapy patients (Bruyere et al., 2005). However, whether the potential positive effects of WBV programs are due to vibration or due to the exercises performed on the platform itself remain unclear (Álvarez-Barbosa et al., 2014). Recently, Sievanen et al. (2012) reported no significant treatment effect on mobility after comparing 10 weeks of an exercise program performed at either low-frequency $(12 \mathrm{~Hz})$ or highfrequency $(16 \mathrm{~Hz})$ with the same exercise program performed on the vibratory device but without the vibration component among nursing home residents. Bautmans et al. (2005) reported on the benefits of 6 weeks static WBV exercise on balance and mobility when compared to the same static exercises performed without vibration among nursing home residents. In order to contribute to the ongoing discussion on whether WBV is a suitable training method for nursing home residents aged $80+$, the aim of this quasi-experimental, pilot trial was to compare the short term responses of nursing home residents aged $80+$ to an exercise (dynamic) program performed on a vibratory device and to the same exercise program (performed on a step of the same dimensions as the vibratory device) without the vibration component on lower limb performance, functional dependence and health-related quality of life. 


\section{MATERIALS AND METHODS}

\section{Participants and study design}

A quasi-experimental study was conducted. The study was approved by the research Ethics Committee of the University of Seville and was conducted in accordance with the Declaration of Helsinki. All participants received written and oral information on the study's aims and procedures. Informed consent was obtained from all individual participants included in the study. Participants in the study were recruited from two nursing home facilities in Seville (Southern Spain). Residents were eligible for the study if they were institutionalized in the nursing home where the study was carried out, if they were at least 80 years old and if they had no major physical (including cardiovascular disease) or cognitive disorder that could prevent them from standing safely on a WBV platform or on a step platform. Potential participants were excluded if they had a pacemaker, knee or hip prosthesis or any other physical, functional or cognitive impairment interfering with testing and training protocols.

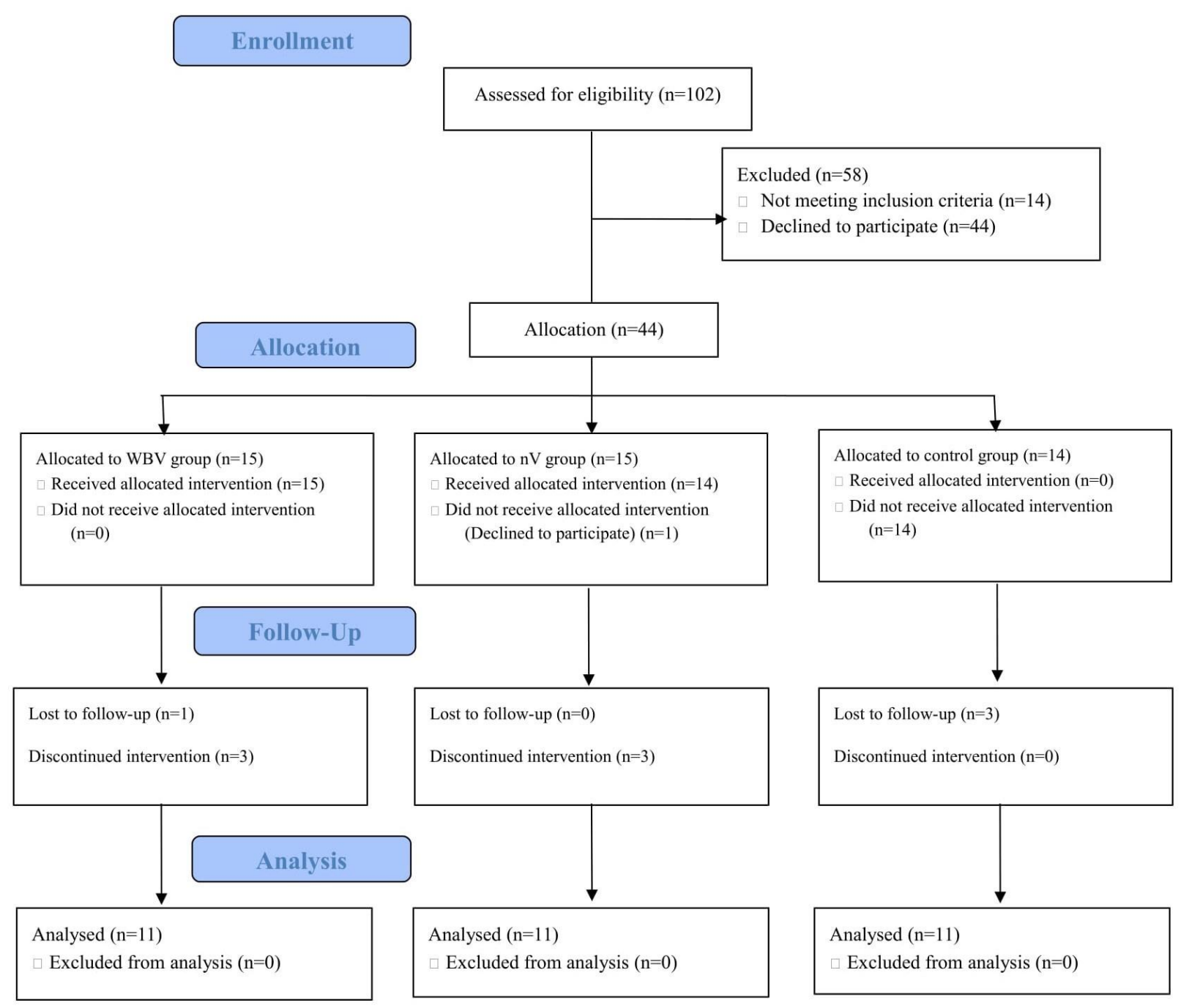

Figure 1. Flow diagram of the participants in the study 
Out of 60 eligible participants in one of the facilities, 35 showed initial interest in the study. However, only 29 fulfilled the inclusion/exclusion criteria and were allocated either into the whole-body vibration group (WBV) or into a control group (CG) using a computer generated random allocation data processing program. Randomization was performed by a member of the research team not directly involved in the recruitment process or assessment of participants. The third study group was recruited from another nursing home facility. Out of 42 potential participants in that facility, 23 showed initial interest in the study. Finally, 15 individuals from that facility were included in the study and allocated into the non-vibration group (nV). A total of 44 subjects participated in the study (Fig 1).

\section{Experimental protocol}

Both the WBV and the nV groups participated in an 8-week exercise-based program consisting of three sessions per week with a rest period of at least one day between sessions, with the same exercises in each treatment session. To warm-up, participants stood three times in an isometric squat position with knees flexed at $100^{\circ}$ for $30 \mathrm{~s}$ with a rest period of $30 \mathrm{~s}$ between each. This exercise was repeated three times. After that, participants were asked to perform 6 exercises (step up and down, lunge, squat, calf raises, left and right pivot in a front and lateral positions) with slow movements at a rate of $3 \mathrm{~s}$ for both concentric and eccentric phases (Table 1). The exercises included have been previously used among older people living in nursing homes (del Pozo-Cruz et al., 2014). The WBV group performed their exercise sessions on a vertical vibratory platform (YV20RS 700, BH, Spain (Table 1). In addition, frequency and amplitude used during the intervention have been previously reported to be safe among this population group (Bautmans et al., 2005; Bogaerts et al., 2011). On the other hand, the non-vibration group performed their exercise sessions on a step platform with the same dimensions as the vibratory device. In both cases, the exercise sessions were supervised by one of the researchers of the study and the physiotherapist of the nursing home. Participants were asked to maintain their usual level of activity out of the intervention sessions. Likewise, the control group was instructed to maintain their usual levels of physical activity and their normal daily life activities over the study period. All participants in the study had access to the usual nursing home care available in public nursing homes in Spain (i.e. nursing care and physiotherapy -mainly mobility exercise sessions).

Table 1

\begin{tabular}{|c|c|c|c|c|c|c|c|c|}
\hline $\begin{array}{c}\text { Week } \\
\mathrm{s}\end{array}$ & $\begin{array}{l}\text { Sessions/ } \\
\text { wk }\end{array}$ & $\begin{array}{l}\text { Warm } \\
\text { up }\end{array}$ & $\begin{array}{l}\text { Numb } \\
\text { er of } \\
\text { exerci } \\
\text { ses }\end{array}$ & $\begin{array}{l}\text { Number } \\
\text { of } \\
\text { repetition } \\
\mathrm{s}\end{array}$ & $\begin{array}{c}\text { Frequency } \\
(\mathrm{Hz}) / \\
\text { Amplitude } \\
(\mathrm{mm})^{*}\end{array}$ & $\begin{array}{l}\text { Rest } \\
\text { peri } \\
\text { od } \\
(\mathrm{s})\end{array}$ & $\begin{array}{c}\text { Total } \\
\text { repetitions }\end{array}$ & $\begin{array}{l}\text { Total session } \\
\text { Time (min) }\end{array}$ \\
\hline $1-2$ & 3 & $\begin{array}{c}3 / 30 \mathrm{~s} / 3 \\
0 \mathrm{~s}\end{array}$ & 6 & 6 & $30 / 4$ & 45 & 48 & 12.3 \\
\hline $3-4$ & 3 & $\begin{array}{c}3 / 30 \mathrm{~s} / 3 \\
0 \mathrm{~s}\end{array}$ & 6 & 8 & $30 / 4$ & 45 & 64 & 13.9 \\
\hline $5-6$ & 3 & $\begin{array}{c}3 / 30 \mathrm{~s} / 3 \\
0 \mathrm{~s}\end{array}$ & 6 & 10 & $35 / 4$ & 45 & 80 & 15.5 \\
\hline $7-8$ & 3 & $\begin{array}{c}3 / 30 \mathrm{~s} / 3 \\
0 \mathrm{~s}\end{array}$ & 6 & 12 & $35 / 4$ & 45 & 96 & 17.1 \\
\hline
\end{tabular}

*Applicable only to the WBV group 


\section{Outcome measures}

Socio-demographic variables were recorded. The body-mass index and waist to hip ratio were calculated. Body-fat percentage was also estimated using an impedance analyser (Omron BF-306, Omron Healthcare Europe BV, Hoofddorp, The Netherlands) (Table 2).

Table 2

Characteristics of the participants in the study $(n=33)$

\begin{tabular}{|c|c|c|c|c|c|}
\hline Variables & Control Group $(\mathrm{n}=11)$ & nV Group (11) & $\begin{array}{l}\text { WBV Group } \\
(\mathrm{n}=11)\end{array}$ & Total $(n=33)$ & $p$ \\
\hline \multicolumn{6}{|l|}{ Socio-economic variables } \\
\hline Age (years) & $85.5(5.5)$ & $86.0(12.0)$ & $84.0(3.0)$ & $85.0(5.7)$ & 0.849 \\
\hline Gender ( $\%$ females $)$ & 81.8 & 63.6 & 72.7 & 72.7 & 0.632 \\
\hline \multicolumn{6}{|l|}{ Body composition } \\
\hline $\operatorname{BMI}\left(\mathrm{Kg} / \mathrm{m}^{2}\right)$ & $29.2(7.2)$ & $27.1(2.4)$ & $26.0(3.4)$ & $27.3(3.6)$ & 0.122 \\
\hline WHR & $0.89(0.1)$ & $0.97(0.12)$ & $0.91(0.1)$ & $0.92(0.1)$ & 0.097 \\
\hline Body fat (\%) & $42.8(6.0)$ & $40.3(9.5)$ & $40.6(11.8)$ & $42.6(10.3)$ & 0.701 \\
\hline \multicolumn{6}{|l|}{ Clinical variables } \\
\hline Institutionalized (years) & $4.1(2)$ & $2.4(0.6)$ & $2(3)$ & $2.5(2.1)$ & 0.070 \\
\hline Diseases (number) & $4(5)$ & $3(2)$ & $3(2)$ & $3(2)$ & 0.130 \\
\hline Diary drugs (number) & $8(6)$ & $6(9)$ & $5(6)$ & $6(6)$ & 0.368 \\
\hline Number of falls & $0(0)$ & $0(0)$ & $0(0)$ & $0(0)$ & 0.332 \\
\hline \multicolumn{6}{|l|}{ Lower limb performance } \\
\hline CSTS-Number of times & $7(2)$ & $6(4)$ & $7(3)$ & $7(3)$ & 0.443 \\
\hline $\operatorname{CSTS}-\operatorname{Vmax}(\mathrm{m} / \mathrm{s})$ & $0.46(0.26)$ & $0.45(0.17)$ & $0.54(0.35)$ & $0.46(0.26)$ & 0.227 \\
\hline CSTS-Vmen (m/s) & $0.41(0.22)$ & $0.36(0.2)$ & $0.48(0.31)$ & $0.39(0.25)$ & 0.161 \\
\hline CSTS-Strength (N) & $787.9(321.36)$ & $787.17(291.56)$ & $644.24(185.16)$ & $768.4(242.8)$ & 0.670 \\
\hline CSTS-Power (N) & $399.48(257.9)$ & $318.38(258.44)$ & $373.29(284.14)$ & $357.3(256.3)$ & 0.490 \\
\hline Timed Up and Go (s) & $14.15(6.2)$ & $15.7(8.1)$ & $11(3.7)$ & $12.75(4.9)$ & 0.061 \\
\hline \multicolumn{6}{|l|}{ Postural Stability } \\
\hline Area eyes open $\left(\mathrm{cm}^{2}\right)$ & $2.43(0.9)$ & $2.22(4.26)$ & $1.39(2.88)$ & $2.11(2.71)$ & 0.401 \\
\hline Area eyes closed $\left(\mathrm{cm}^{2}\right)$ & $3.30(2.96)$ & $2.79(2.63)$ & $1.71(2.99)$ & $2.90(2.68)$ & 0.688 \\
\hline $\begin{array}{c}\text { Area cognitive } \\
\text { interference }\left(\mathrm{cm}^{2}\right)\end{array}$ & $2.03(2.15)$ & $2.60(2.02)$ & $1.43(2.84)$ & $2.07(2.26)$ & 0.458 \\
\hline \multicolumn{6}{|l|}{ Functional dependence } \\
\hline Barthel index & $85(30)$ & $85(35)$ & $95(10)$ & $90(22.5)$ & 0.207 \\
\hline \multicolumn{6}{|l|}{ Quality of life } \\
\hline EQ-5D utility index & $0.78(0.15)$ & $0.73(0.28)$ & $0.88(0.10)$ & $0.78(0.17)$ & 0.141 \\
\hline EQ-5D-vas & $70(45)$ & $70(40)$ & $80(35)$ & $70(40)$ & 0.712 \\
\hline
\end{tabular}

Functional mobility was assessed using the Time Up and Go (TUG) test (Podsiadlo \& Richardson, 1991). Participants had to stand up from a standard chair, walk 3 meters to and around a cone, and then return to the chair in a comfortable and safe walking speed (Podsiadlo \& Richardson, 1991). The best time of two trials (1-minute rest period between each trial) was recorded. An increase equal to or greater than 0.8-1.2 seconds for Time Up and Go (TUG) test has been established as minimal clinically important difference (Wright et al., 2011).

Lower limb muscle performance was assessed using the 30 seconds Chair Sit to Stand (30-s CSTS) test (Álvarez-Barbosa et al., 2014; Rikli \& Jones, 2013; Thapa et al., 1994). The task started and finished in a seated position. Participants were allowed a practice trial before the beginning of the test. The number of times within $30 \mathrm{~s}$ that the participant could raise to a full stand from a seated position as fast as possible, with their back straight and feet flat on the floor without pushing off using their arms, was counted. The maximum speed of each repetition as well as the average speed while standing-up were recorded with a Linear Encoder (Model TF-100, T-Force System Ergotech, Murcia, Spain) and the peak force was recorded using a Kistler force platform, type 9281A (Kistler Instruments AG, Winterthur, Switzerland). The maximum power during 
the test could then be calculated. An increase equal to or greater than 2-2.6 times for 30-s CSTS test has been established as minimal clinically important difference (Wright et al., 2011).

Postural stability was measured using a Kistler force platform by recording the anterior-posterior (AP) and medial-lateral (ML) centre of pressure (COP) excursions while in a quiet standing posture. Sway ellipse area $\left(\mathrm{cm}^{2}\right)$ was calculated 3 times each with increasing postural difficulty: (i) standing on the force platform with the eyes open, (ii) standing on the force platform with the eyes open (cognitive task) and (iii) standing on the force platform with the eyes closed. For each condition, 3 trials were performed. Each trial lasted for $30 \mathrm{~s}$ and was followed by a rest period of $1 \mathrm{~min}$. In this case, only the final $20 \mathrm{~s}$ were analysed (Prieto et al., 1996). The cognitive task was counting backwards as fast and as accurately as possible by 3 while performing the standing task, beginning with a randomly selected number from a range of 100-200. Data were sampled at $1000 \mathrm{~Hz}$ and transformed to obtain COP area values.

The Barthel Index (BI) of activities of daily living (Mahoney \& Barthel, 1965) was used to measure performance in ADLs of the participants in the study and the EuroQol-5D (EQ-5D) (EuroQol Group, 1990) was used to assess participants health-related quality of life (HRQLL).

\section{Statistical analysis}

Data analysis was carried out using the statistical software program SPSS for Windows V.17.0 (SPSS Inc., Chicago, IL). The Shapiro Wilk test was used to test the normality of data. After non-parametric distribution was confirmed, differences at baseline between groups were analysed using either Kruskal-Wallis $\mathrm{H}$ test or chi-square test. Between-groups comparisons after treatment were analysed using Kruskal-Wallis $\mathrm{H}$ test and post hoc comparison were performed with Mann-Whitney U test with Bonferroni correction. Wilcoxon test was performed to determinate the pre to post treatment intra-group differences. Median (IQR) was used as a descriptive statistic. Significance level was set at $p<.05$ for all analyses.

\section{RESULTS}

Forty-four nursing home residents were finally included in the study (Figure 1). None of the participants in the intervention groups reported any adverse health effects during the treatment. In the WBV group, 73\% (11 out of 15) of participants completed at least $80 \%$ of the sessions offered in the program. In the nV group, $80 \%$ (12 out of 15) of participants completed at least $80 \%$ of the sessions offered and 1 participant declined to participate before the study began, so finally $73 \%$ of participants in the $\mathrm{nV}$ were included in the analysis. In the CG, $78 \%$ of the participants were assessed at baseline and after the program and were included in the statistical analysis. Only those participants with pre and post treatment data on all assessed outcomes (i.e. 33/44) were included in the statistical analysis. No significant differences between groups were detected at baseline for any of the study variables (Table 2).

\section{Between group comparisons}

Statistically significant differences after an 8-week treatment were detected between groups in lower limb muscle performance [i.e. CSTS-number of times $(p=0.001)$ ], mobility [TUG $(p=0.001)$ ], functional independence [Barthel index $(p=0.009)$ and Barthel interpretation $(p=0.012)]$ and quality of life [EQ-5d utility $(p<0.001), E Q-5 D$ vas $(p=0.046)$ ] (figure $2 a$ and $2 b)$. No significant differences between groups in postural stability were found (figure 2c). Pairwise comparisons revealed significant improvement on TUG ( $p=0.001$ and $p<0.000$ ), CSTS (number of times; $p=0.006$ and $p<0.000$ ), EQ-5D (utility; $p=0.003$ and $p<0.000$ ) in the WBV group when compared with $\mathrm{nV}$ group and $\mathrm{CG}$. 
Median changes (IQR) in 30-s Chair Sit to Stand test related variables and Time Up and Go test score over the 8-wk treatment. a denotes positive (i.e., the score getting better within the group after the treatment period) intra-group statistically significant differences. $b$ denotes negative (i.e., the score getting worse within the group after the treatment period). $c$ denotes significant changes as compared to the other two groups after pairwise comparison.
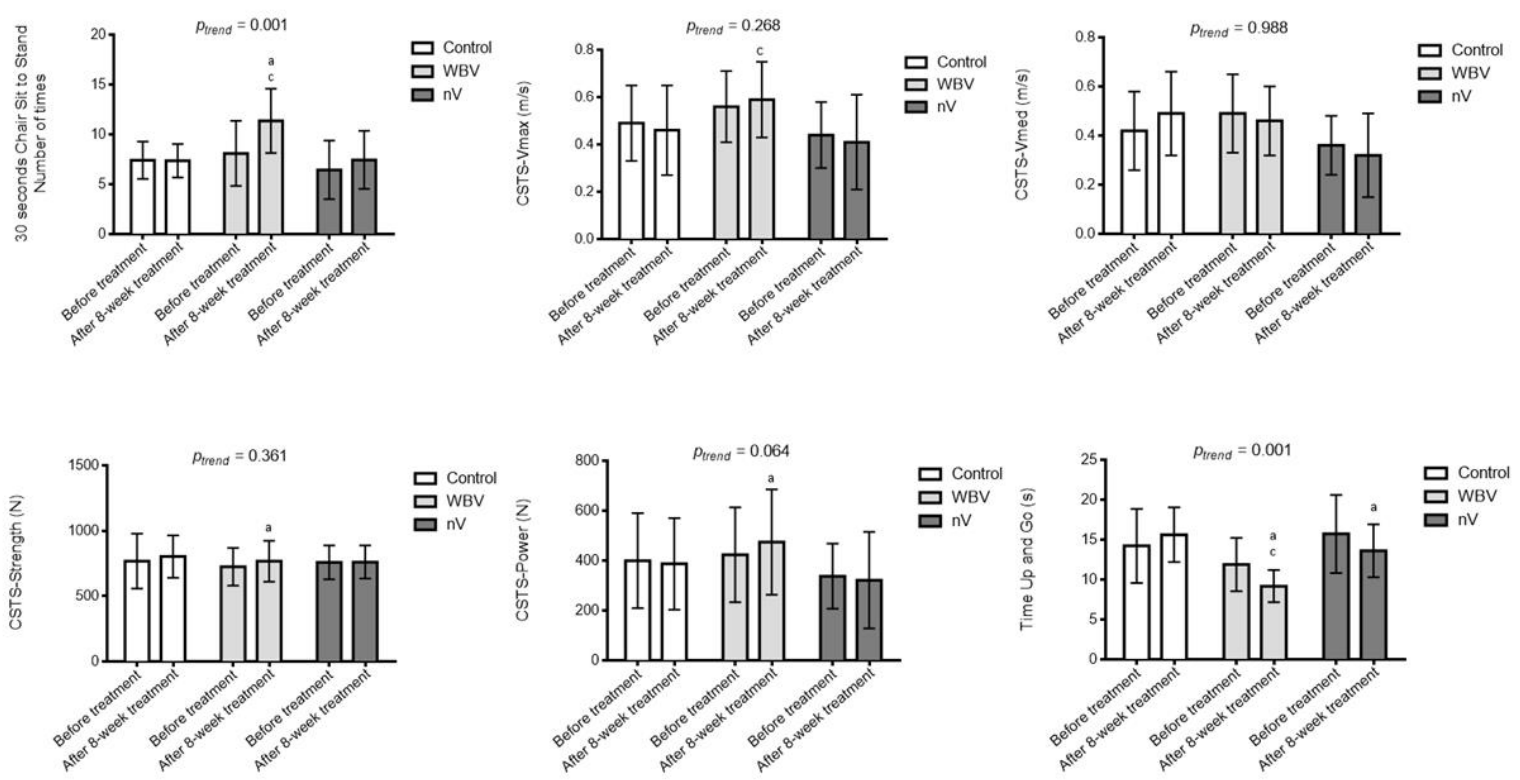

Fig 2a. Lower limb performance and mobility outcomes. Median changes (IQR) in 30-s Chair Sit to Stand test related variables and Time Up and Go test score over the 8-wk treatment. a denotes positive (i.e., the score getting better within the group after the treatment period) intra-group statistically significant differences. $b$ denotes negative (i.e., the score getting worse within the group after the treatment period). c denotes significant changes as compared to the other two groups after pairwise comparison. 

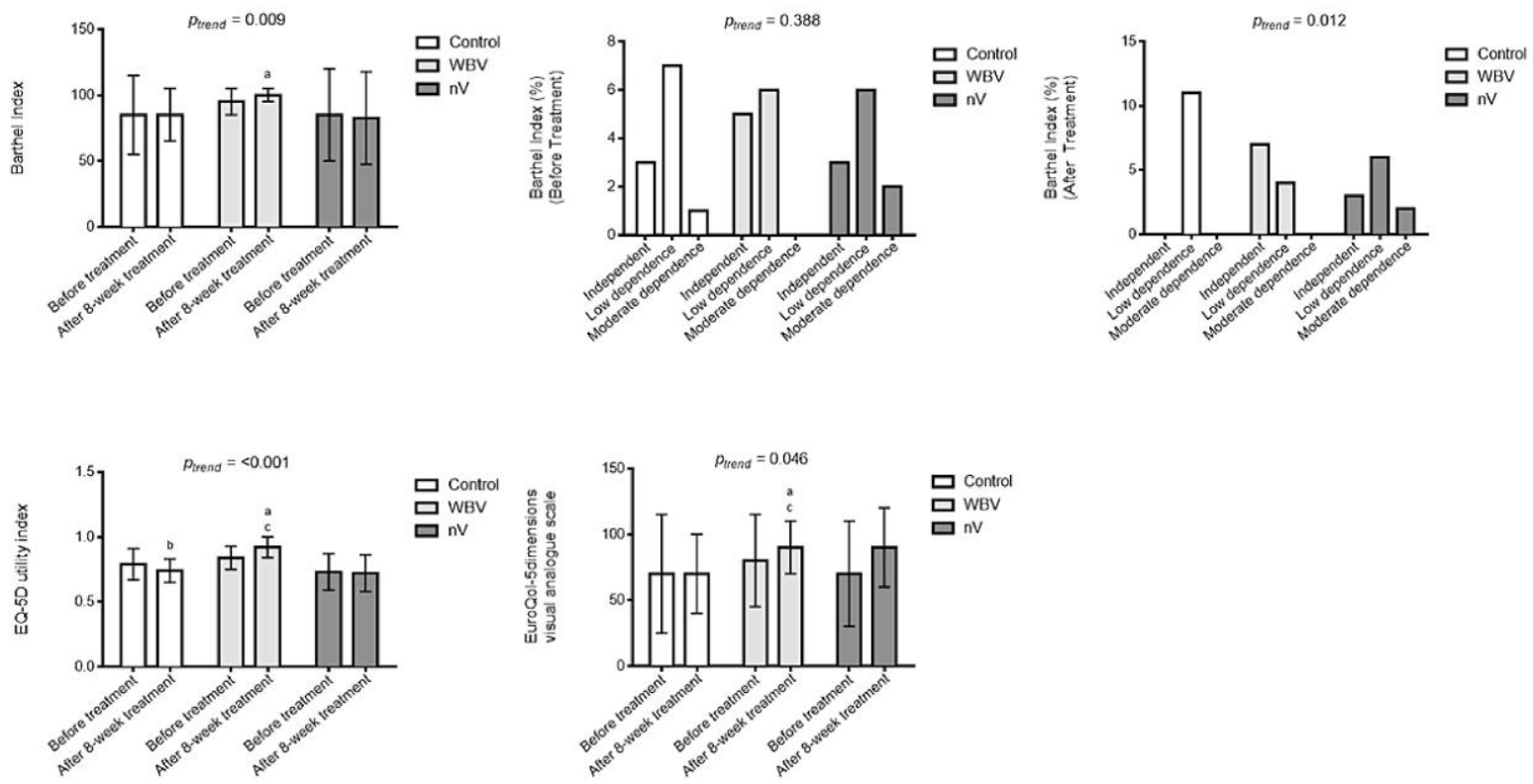

Figure $2 b$. Functional dependence and quality of life outcomes. Median changes (IQR) in activity of daily fife performance as assessed by The Barthel Index) and health-related quality of life as assessed by The EuroQol over the 8-wk treatment. a denotes positive (i.e., the score getting better within the group after the treatment period) intra-group statistically significant differences. $b$ denotes negative (i.e., the score getting worse within the group after the treatment period). $c$ denotes significant changes as compared to the other two groups after pairwise comparison.
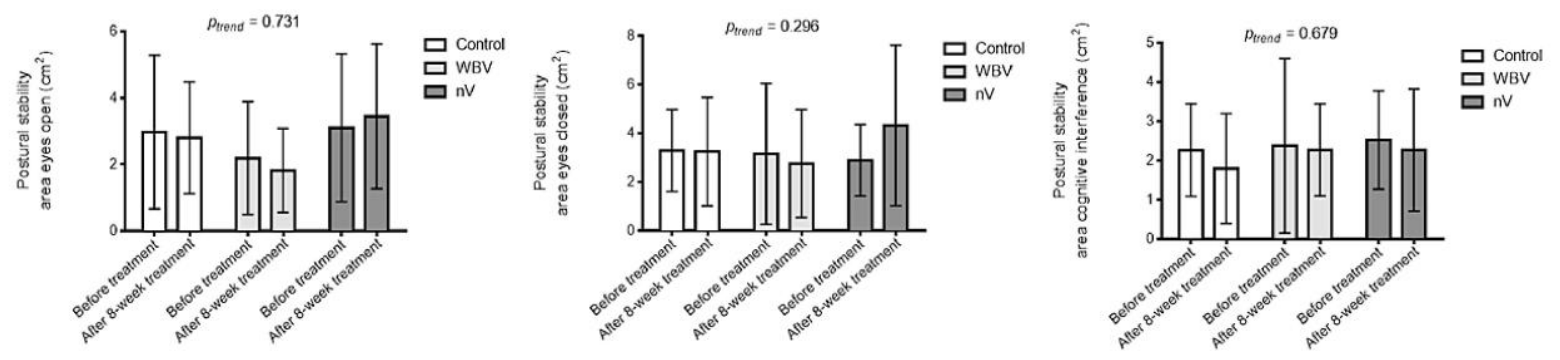

Figure 2c. Postural stability outcomes. Median changes (IQR) in postural stability assessed with the force platform during eyes-open test $(\mathrm{OA})$, eyes-closed $(\mathrm{OC})$ and cognitive interference (IC) over the 8-wk treatment.

\section{Within-group comparisons}

In addition, intra-group analysis showed that, after 8 weeks of training, there was a statistically significant improvement in TUG score test in the WBV group $(-2.71 \mathrm{~s} ; \mathrm{p}=0.006)$ as well as in non-vibration group $(-2.12 \mathrm{~s}$; $p=0.008)$. Improvements were also detected in CSTS-number of times $(+3.54 ; p=0.002)$, CSTS-power $(+50.49 \mathrm{~N} ; \mathrm{p}=0.012)$ CSTS-force $(+42.63 \mathrm{~N} ; \mathrm{p}=0.048)$, and $\mathrm{EQ}-5 \mathrm{D}_{\text {utility index }}(+0.08 ; \mathrm{p}=0.002)$ and $\mathrm{EQ}-5 \mathrm{Dvas}$ $(+16.27 ; p=0.022)$ in participants in the WBV group (Figure 2a, 2b). 
Median changes (IQR) in activity of daily fife performance as assessed by The Barthel Index) and healthrelated quality of life as assessed by The EuroQol over the 8-wk treatment. a denotes positive (i.e., the score getting better within the group after the treatment period) intra-group statistically significant differences. $b$ denotes negative (i.e., the score getting worse within the group after the treatment period). c denotes significant changes as compared to the other two groups after pairwise comparison.

Median changes (IQR) in postural stability assessed with the force platform during eyes-open test $(\mathrm{OA})$, eyesclosed (OC) and cognitive interference (IC) over the 8-wk treatment.

\section{DISCUSSION}

The present study aimed at contributing to the ongoing discussion on the use of WBV as an alternative training method for frail elderly people (in this case, nursing home residents aged $80+$ ) by conducting a small, quasi-experimental study comparing the short term responses of nursing home residents aged $80+$ to an exercise (dynamic) program performed on a vibratory device and to the same exercise program (performed on a step of same dimensions as the vibratory device) without the vibration component on lower limb muscle performance, health-related quality of life and functional dependence. The main findings were that those participants that exercised on the vibration platform improved their lower limb muscle performance, mobility and health-related quality of life when compared to both the $\mathrm{nV}$ group and CG.

Intra-group analysis shows that WBV and the $\mathrm{nV}$ group significantly (clinical improvements) lowered the time spent in perform TUG test. However, only WBV group showed significant improvements compared with CG $(p<0.001)$. Bautmans et al. (2005), also found that WBV is feasible and might provide better benefits for mobility than static exercise in nursing home residents. This could be justified by the evidence suggesting that vibration is effective in enhancing strength and power capacity in humans (Cardinale \& Bosco, 2003). This could explain the decrease in time for the WBV group compared to the CG $(+0.59 \mathrm{~s})$. Several studies have also reported the effectiveness of WBV to improve gait and mobility as assessed by the TUG test among nursing home elderly people (Bogaerts et al., 2011; Bruyere et al., 2005). Nonetheless, the fact that participants in the WBV group scored better in the TUG test than participants in the nV group suggests that WBV may be a promising therapy to clinically improve gait function and mobility among nursing home residents aged $80+$ (Shimada et al., 2011).

We observed intra-group improvements in lower limb muscle strength and power in the WBV group. However, we failed to observe any improvement for those outcomes in either the $\mathrm{nV}$ group or the CG after the program. Thus, the WBV group did more sit to stand cycles in the 30-s CSTS test $(+3.54 ; p=0.002)$ as compared to the other two groups after the treatment. This absolute change for the WBV group is considered clinically relevant according to previous studies since the improvement was more than 2-2.6 times greater (Wright et al., 2011). These results are consistent with those obtained in another study that concluded that the addition of vibration to resistance exercise resulted in better functional outcomes than the same exercise program performed without vibration in a group of frail older adults (Pollock et al., 2012). Therefore, our findings reinforce the idea that WBV may induce further benefits on lower limb muscle performance as compared to conventional training. One potential explanation may be that vibration causes changes in muscle length so muscle spindles activated alpha motor neurons, thus increasing the recruitment and activation of the agonist muscles that enhances the neuromuscular system (Burke \& Schiller, 1976; Rittweger, 2010). On the other hand, a relationship between muscle weakness (i.e. reduced strength) and fall risk had been previously reported (Marques et al., 2013). Thus, we hypothesise that improvements in lower limb muscle performance 
may lead to fall risk prevention and a reduction in actual falls. Studies investigating long-term fall incidence among nursing home residents using WBV are warranted.

The fact that the participants belonging to the intervention groups (i.e. WBV and nV) were required to make the effort to climb to a step or a vibration platform could contribute to the improvements on the parameters assessed. Despite this, both groups made the same effort and yet, the WBV group obtained more benefits than the $\mathrm{nV}$, suggesting the beneficial effects of WBV. However, we cannot discern whether the effort to climb to the platform might have something to do with the differences found in the control group, whose participants did not make such effort.

Additionally, those participants that followed the WBV-based training reported a better performance in their activities of daily living as assessed with the Barthel index. This could reflect the fact that participants in the WBV group also showed an improvement in lower limb muscle power. In fact, lower limb muscle power is considered one of the key predictors of functional dependency in older adults (Foldvari et al., 2000) and improvements could lead to a greater ability to perform activities of daily living and prevention of further disability (Cadore et al., 2014). Consequently, participants in the WBV group self-reported a better healthrelated quality of life as compared to the $\mathrm{nV}$ group or CG. Thereby, our results support the idea that WBV is effective in improving health-related quality of life among older adults living in nursing homes (ÁlvarezBarbosa et al., 2014; Bruyere et al., 2005).

We failed to detect any statistically significant differences between the three groups and within-groups over the course of the study regarding static balance outcomes assessed in the current study. Previous studies have yielded similar conclusions. Mikhael et al. (2010) found that after 12-weeks of WBV-based therapy, a group of community-dwelling elderly people improved their lower limb muscle performance (i.e. strength and muscle speed contraction) but they did not find any effects on static balance. Another study on institutionalized elderly women did not even find any improvement on lower limb muscle performance or static balance after 6-months of WBV-based therapy (Bogaerts et al., 2011). There are a number of plausible reasons that may explain this issue. The first is the kind of vibration stimulus produced by a vertical vibration platform (Álvarez-Barbosa et al., 2014). The second could be that a conservative dose of WBV was used, and the third could be that a dynamic exercise program was performed which did not specifically target static balance of the participants (Álvarez-Barbosa et al., 2014).

This study has a number of limitations that should be taken into account to correctly interpret the results obtained. The major limitation is the randomization of the sample, since participants from $\mathrm{nV}$ group belong to a different nursing home than WBV and control groups. However, nursing care offered similar standard cares and dependency level was similar among participants in the three study groups. In fact, none of the study variables showed statistically significant differences at baseline. Secondly, the small sample size could limit the generalization of the results. In addition, outcomes were assessed by one of the researchers who was not blinded. However, the present study was carried out as a pilot trial. Other studies might want to replicate the current study using a better research design. Another shortcoming was that the participants in the WBV group did wear their own shoes, so a potential damping of the vibration could have occurred. Given the characteristics of participants, researchers thought that asking participants to remove their shoes may compromise participation rates. Education on the importance of that aspect before starting the program may help overcome this limitation. Lastly, free-living physical activity was not assessed and therefore results were not adjusted. The fact that a conservative dose of WBV (i.e. low frequencies and amplitudes) was used in this study may account for the lack of a training effect on some of the outcomes in the study. Studies testing the optimal dose-response are therefore necessary. 


\section{CONCLUSION}

The results of this study suggest that the vibratory component of the WBV therapy may add additional benefits to similar programs performed without the vibratory component when dynamic exercises are performed in terms of lower limb muscle performance, functional dependence and quality of life improvements among nursing home residents age $80+$. In practice, these findings strengthen the idea that WBV could be implemented in nursing home facilities to address some key fall-related factors (Álvarez-Barbosa et al., 2014; Bruyere et al., 2005). However, studies with better (more controlled) research designs and larger sample sizes are required in order to confirm these results. Future cost-effective analysis may add value to the current conclusion in terms of decision-making process.

\section{REFERENCES}

Almomani, F. M., McDowd, J. M., Bani-Issa, W. \& Almomani, M. (2014). Health-related quality of life and physical, mental, and cognitive disabilities among nursing home residents in Jordan. Quality of Life Research, 23(1), 155-165. http://doi.org/10.1007/s11136-013-0461-2

Álvarez-Barbosa, F., Pozo-Cruz, J., Pozo-Cruz, B., Alfonso-Rosa, R. M., Rogers, M. E. \& Zhang, Y. (2014). Effects of supervised whole body vibration exercise on fall risk factors, functional dependence and health-related quality of life in nursing home residents aged 80+. Maturitas, 79(4), 456-463. http://doi.org/10.1016/..maturitas.2014.09.010

Bautmans, I., Van Hees, E., Lemper, J. C. \& Mets, T. (2005). The feasibility of Whole Body Vibration in institutionalised elderly persons and its influence on muscle performance, balance and mobility: a randomised controlled trial [ISRCTN62535013]. BMC Geriatr, 5, 17. http://doi.org/10.1186/1471$\underline{2318-5-17}$

Bogaerts, A. C. G., Delecluse, C., Claessens, A. L., Troosters, T., Boonen, S. \& Verschueren, S. M. P. (2009). Effects of whole body vibration training on cardiorespiratory fitness and muscle strength in older individuals (a 1-year randomised controlled trial). Age and Ageing, 38(4), 448-54. http://doi.org/10.1093/ageing/afp067

Bogaerts, A., Delecluse, C., Boonen, S., Claessens, A. L., Milisen, K. \& Verschueren, S. M. P. (2011). Changes in balance, functional performance and fall risk following whole body vibration training and vitamin $D$ supplementation in institutionalized elderly women. A 6 month randomized controlled trial. Gait \& Posture, 33(3), 466-472. https://doi.org/10.1016/i.gaitpost.2010.12.027

Bruyere, O., Wuidart, M.-A., Di Palma, E., Gourlay, M., Ethgen, O., Richy, F. \& Reginster, J.-Y. (2005). Controlled Whole Body Vibration to Decrease Fall Risk and Improve Health-Related Quality of Life of Nursing Home Residents. Archives of Physical Medicine \& Rehabilitation, 86(2), 303-307. https://doi.org/10.1016/i.apmr.2004.05.019

Burke, D. \& Schiller, H. H. (1976). Discharge pattern of single motor units in the tonic vibration reflex of human triceps surae. J Neurol Neurosurg Psychiatry, 39(8), 729-741. https://doi.org/10.1136/innp.39.8.729

Cadore, E. L., Casas-Herrero, A., Zambom-Ferraresi, F., Idoate, F., Millor, N., Gómez, M. \& Izquierdo, M. (2014). Multicomponent exercises including muscle power training enhance muscle mass, power output, and functional outcomes in institutionalized frail nonagenarians. AGE, 36(2), 773-785. http://doi.org/10.1007/s11357-013-9586-z

Cardinale, M. \& Bosco, C. (2003). The use of vibration as an exercise intervention. Exerc Sport Sci Rev, 31(1), 3-7. https://doi.org/10.1097/00003677-200301000-00002 
Chou, C. H., Hwang, C. L. \& Wu, Y. T. (2012). Effect of exercise on physical function, daily living activities, and quality of life in the frail older adults: A meta-analysis. Archives of Physical Medicine and Rehabilitation, 93(2), 237-244. http://doi.org/10.1016/i.apmr.2011.08.042

del Pozo-Cruz, B., Alfonso-Rosa, R. M., del Pozo-Cruz, J., Sañudo, B. \& Rogers, M. E. (2014). Effects of a 12-wk whole-body vibration based intervention to improve type 2 diabetes. Maturitas, 77(1), 52 8. http://doi.org/10.1016/i.maturitas.2013.09.005

EuroQol Group. (1990). EuroQol--a new facility for the measurement of health-related quality of life. Health Policy (Amsterdam, Netherlands), 16(3), 199-208. Retrieved from http://www.ncbi.nlm.nih.gov/pubmed/10109801

Foldvari, M., Clark, M., Laviolette, L. C., Bernstein, M. A., Kaliton, D., Castaneda, C. \& Singh, M. A. (2000). Association of muscle power with functional status in community-dwelling elderly women. J Gerontol A Biol Sci Med Sci, 55(4), M192-9. https://doi.org/10.1093/gerona/55.4.M192

Gine-Garriga, M., Roque-Figuls, M., Coll-Planas, L., Sitja-Rabert, M. \& Salva, A. (2014). Physical exercise interventions for improving performance-based measures of physical function in community-dwelling, frail older adults: a systematic review and meta-analysis. Arch Phys Med Rehabil, 95(4), 753-769 e3. http://doi.org/10.1016/i.apmr.2013.11.007

Kadono, N. \& Pavol, M. J. (2013). Effects of aging-related losses in strength on the ability to recover from a backward balance loss. Journal of Biomechanics, 46(1), 13-8. http://doi.org/10.1016/i.jbiomech.2012.08.046

Lam, F. M., Lau, R. W., Chung, R. C. \& Pang, M. Y. (2012). The effect of whole body vibration on balance, mobility and falls in older adults: a systematic review and meta-analysis. Maturitas, 72(3), 206-213. http://doi.org/10.1016/..maturitas.2012.04.009

Mahoney, F. I. \& Barthel, D. W. (1965). Functional Evaluation: The Barthel Index. Md State Med J, 14, 61-65. Retrieved from http://www.ncbi.nlm.nih.gov/pubmed/14258950

Marques, N. R., LaRoche, D. P., Hallal, C. Z., Crozara, L. F., Morcelli, M. H., Karuka, A. H. \& Goncalves, M. (2013). Association between energy cost of walking, muscle activation, and biomechanical parameters in older female fallers and non-fallers. Clin Biomech (Bristol, Avon), 28(3), 330-336. http://doi.org/10.1016/i.clinbiomech.2013.01.004

Mikhael, M., Orr, R., Amsen, F., Greene, D. \& Singh, M. A. (2010). Effect of standing posture during whole body vibration training on muscle morphology and function in older adults: a randomised controlled trial. BMC Geriatr, 10, 74. http://doi.org/10.1186/1471-2318-10-74

Nitz, J. C. \& Josephson, D. L. (2011). Enhancing Functional Balance and Mobility Among Older People Living in Long-Term Care Facilities. Geriatric Nursing, 32(2), 106-113. http://doi.org/10.1016/i.gerinurse.2010.11.004

Podsiadlo, D. \& Richardson, S. (1991). The timed "Up \& Go": a test of basic functional mobility for frail elderly persons. J Am Geriatr Soc, 39(2), 142-148. https://doi.org/10.1111/i.15325415.1991.tb01616.x

Pollock, R. D., Martin, F. C. \& Newham, D. J. (2012). Whole-body vibration in addition to strength and balance exercise for falls-related functional mobility of frail older adults: a single-blind randomized controlled trial. Clin Rehabil, 26(10), 915-923. http://doi.org/10.1177/0269215511435688

Prieto, T. E., Myklebust, J. B., Hoffmann, R. G., Lovett, E. G. \& Myklebust, B. M. (1996). Measures of postural steadiness: differences between healthy young and elderly adults. IEEE Trans Biomed Eng, 43(9), 956-966. http://doi.org/10.1109/10.532130

Rikli, R. E. \& Jones, C. J. (2013). Senior fitness test manual. Human Kinetics. Retrieved from https://books.google.es/books?hl=es\&lr=\&id=NXfXxOFFOVwC\&oi=fnd\&pg=PR1\&dq=rikli+re+jones + +cj.+senior+fitness+test+manual.+champaign+il+human+kinetics+2001\&ots=cT1G90pfN\&sig=czAA CNrPiZW0ttYDHrldS5MUTo\#v=onepage\&q\&f=false 
Rittweger, J. (2010). Vibration as an exercise modality: how it may work, and what its potential might be. Eur J Appl Physiol, 108(5), 877-904. http://doi.org/10.1007/s00421-009-1303-3

Rubenstein, L. Z. \& Josephson, K. R. (2002). The epidemiology of falls and syncope. Clinics in Geriatric Medicine, 18(2), 141-158. http://doi.org/10.1016/S0749-0690(02)00002-2

Sherrington, C., Tiedemann, A., Fairhall, N., Close, J. C. \& Lord, S. R. (2011). Exercise to prevent falls in older adults: an updated meta-analysis and best practice recommendations. N S W Public Health Bull, 22(3-4), 78-83. http://doi.org/10.1071/NB10056

Sherrington, C., Whitney, J. C., Lord, S. R., Herbert, R. D., Cumming, R. G. \& Close, J. C. (2008). Effective exercise for the prevention of falls: a systematic review and meta-analysis. J Am Geriatr Soc, 56(12), 2234-2243. http://doi.org/10.1111/j.1532-5415.2008.02014.x

Shimada, H., Tiedemann, A., Lord, S. R., Suzukawa, M., Makizako, H., Kobayashi, K. \& Suzuki, T. (2011). Physical factors underlying the association between lower walking performance and falls in older people: A structural equation model. Archives of Gerontology and Geriatrics, 53(2), 131-134. http://doi.org/10.1016/i.archger.2010.11.003

Sievanen, H., Karinkanta, S., Moisio-Vilenius, P. \& Ripsaluoma, J. (2012). Effect of whole body vibration training on physical performance among institutionalized older people: A 10-WK pilot blinded randomized controlled trial. Osteoporosis International, 23, S83-S84. Retrieved from http://ovidsp.ovid.com/ovidweb.cgi? T=JS\&CSC=Y\&NEWS=N\&PAGE=fulltext\&D=emed10\&AN=707 41198

Sousa-Victor, P., García-Prat, L., Serrano, A. L., Perdiguero, E. \& Muñoz-Cánoves, P. (2015). Muscle stem cell aging: regulation and rejuvenation. Trends in Endocrinology \& Metabolism, 26(6), 287296. http://doi.org/10.1016/j.tem.2015.03.006

Thapa, P. B., Gideon, P., Fought, R. L., Kormicki, M. \& Ray, W. A. (1994). Comparison of clinical and biomechanical measures of balance and mobility in elderly nursing home residents. J Am Geriatr Soc, 42(5), 493-500. https://doi.org/10.1111/j.1532-5415.1994.tb04970.x

Wolfson, L. (2001, April 29). Gait and balance dysfunction: A model of the interaction of age and disease. Neuroscientist. http://doi.org/10.1177/107385840100700212

Wright, A. A., Cook, C. E., Baxter, G. D., Dockerty, J. D. \& Abbott, J. H. (2011). A comparison of 3 methodological approaches to defining major clinically important improvement of 4 performance measures in patients with hip osteoarthritis. J Orthop Sports Phys Ther, 41(5), 319-327. http://doi.org/10.2519/jospt.2011.3515

\section{@) $\mathbb{Q \Theta \Theta}$}

This work is licensed under a Attribution-NonCommercial-NoDerivatives 4.0 International (CC BY-NC-ND 4.0). 